\title{
Abstração e crítica de arte no diálogo Brasil-Japão (1950-1960)
}

\author{
Victor Raphael Rente Vidal \\ DOI 10.20396/eha.vi14.3455
}

Em 1958, Mário Pedrosa passou seis meses na cidade de Tóquio como bolsista da UNESCO na condição de pesquisador visitante no Museu Nacional de Arte Moderna; a bolsa foi conquistada como prêmio oferecido durante o Congresso de Críticos de Arte que ocorreu em Brasília. Durante esse período, Pedrosa estudou as influências da caligrafia sino-japonesa na arte abstrata europeia, organizou uma exposição no próprio Museu Nacional sobre a arquitetura de Brasília e escreveu sobre sua experiência com críticos e artistas japoneses em sua coluna no Jornal do Brasil.

No artigo "Arte - Japão \& Ocidente", Pedrosa apresenta aos leitores da sua coluna algumas impressões das exposições que visitou em Tóquio durante o mês de setembro daquele ano. O crítico inicia seus comentários atentando para uma mostra de arte gráfica e revela o desejo de que o evento ocorra também no Brasil, uma vez que ele acredita que as obras apresentadas, sobretudo os cartazes, seriam preciosas para os artistas brasileiros. "Nela [na exposição], todo o rico senso ornamental do japonês está presente, bem como seu insuperável poder inventivo. Os nossos jovens concretistas veriam nela muita coisa que andam fazendo"2.

Após destinar alguns parágrafos do texto para comentar como o Japão estaria perto de realizar uma integração das artes na sociedade, Pedrosa volta sua atenção para as exposições que visitou e centra seus comentários naquela que foi a exposição “(...) mais fraca de quantas já vi em Tóquio"3. Trata-se da mostra "A arte internacional de uma nova era - Informal e Cutai", curada por Michel Tapié e Jiro Yoshihara. A mostra foi composta por três núcleos, uma centrada nos artistas do grupo Gutai (1954-1972, Osaka), outra voltada aos artistas norte-americanos e uma terceira reunindo artistas europeus. O desagrado de Pedrosa em relação à exposição é notório desde o principio ao se referir a Tapié como um “desses parisienses espertos que, (...), inventam 'ismos' e descobrem 'gênios' todos os dias" 4 . Sobre os artistas do grupo Gutai, Pedrosa não é mais lisonjeiro: "Os japoneses

\footnotetext{
1 Universidade Federal do Rio de Janeiro, Mestre em Estudos Críticos das Artes.

2 PEDROSA, Mário; ARANTES, Otília (org). Modernidade cá e lá: Textos escolhidos IV. São Paulo, Editora da Universidade de São Paulo, 2000 , p. 309.

3 Idem, ibidem, p. 311.

4 Idem.
} 
do Gutai ainda não saíram da fase de escolares que imitam a maneira de um Pollock, (...)”5. Parece importante para Pedrosa, no entanto, deixar claro que, embora a palavra "Gutai" possa ser traduzida como "concreto", o grupo japonês não guarda qualquer semelhança com os grupos concretos no Brasil. "Seja como for, o Grupo Gutai nada tem com o grupo concreto daí. São 'tachistas' e procuram antes o pretenso informe das origens do que a definição de estruturas novas"7.

A rejeição de Mário Pedrosa pela abstração expressiva, ou tachismo, ou informalismo, é amplamente conhecida, uma vez que considerava esse movimento sem engajamento político; em sua opinião, o informalismo era “(...) culturalmente contra o Brasil, não representava esse esforço construtivo que devia estar na cultura brasileira"8. Após abandonar o projeto de compreensão de uma arte voltada ao proletariado, exemplificada em suas análises da obra de Käthe Kollwitz, Pedrosa afirmou que a função da pintura na sociedade não era mais aquela de outros tempos quando o pintor realizava retratos de figuras honorificas ou elaborava cenas religiosas e mitológicas. Com o desenvolvimento da câmera fotográfica, a pintura e o pintor tenderiam a ser um anacronismo nos dias atuais.

Sobre o papel da abstração geométrica no desenvolvimento da cultura brasileira nos anos 1950, Pedrosa comenta:

O Brasil é um país de construção nova e eu achava que a arte concreta foi que deu essa disciplina no nível da forma. Já o informalismo era uma arte pessimista, muito pessimista e refletiu o que se passava no mundo. Uma arte de posição filosófica toda subjetiva, introjetiva. Era uma posição que não implicava uma mensagem, uma atitude de quem vê mais longe. Era um grito do artista, uma interjeição permanente. Eu acho que era simpática, mas uma arte moderna como essa não carregava uma mensagem mundial. Mundial sim, mas perdidamente, sem uma diretriz. A arte moderna foi uma arte que trouxe a esperança de uma civilização mundial e teve essa esperança negada9.

Pedrosa considerava a abstração expressiva como mero produto de uma exteriorização das emoções do artista, ela apenas serviria como mediação entre o autor e o espectador. As formas apresentadas seriam gratuitas, “(...) não é de essência, mas de capricho, de virtuosidade”10. Nesse

\footnotetext{
5 Idem, ibidem, p. 313.

6 "A palavra em si é formada por dois caracteres: 'gu', significando ferramenta ou meio, e 'tai', que significa corpo ou substância; é traduzido como 'concreto'" (BOIS; BUCHLOH; FOSTER; KRAUSS, 2004, p. 374).

7 PEDROSA, ARANTES, op. cit., p. 311.

8 COCHIARALE, Fernando; GEICER, Anna Bella (org.). Abstracionismo geométrico e informal: a vanguarda brasileira nos anos cinquenta. Rio de Janei-

ro: FUNARTE, Instituto Nacional de Artes Plásticas, 1987, p. 107.

9 Idem.

10 PEDROSA, Mário. Mundo, homem, arte em crise. São Paulo: Editora Perspectiva, 2007, p. 47.
} 
sentido, as obras provenientes desse processo de exteriorização apresentariam resultados menos complexos, uma vez que esses artistas interromperiam o processo criativo em sua primeira fase, a fase da projeção. Todo o artista atravessaria a fase da projeção e prosseguiria com seu processo criativo até atingir uma simplificação via complexidade das suas propostas. Sobre os informalistas e a projeção de interioridades, Pedrosa conclui:

Os artistas ficam assim balançando entre um hedonismo estético (gênero Mathieu) e outra espécie de hedonismo dito de ordem moral, gênero Pollock, Kline ou Feito. No fundo, trata-se de um compromisso não-estético; hedonismo tomado num sentido de que há um interesse (logo um prazer), uma consideração prática em jogo; tratar-se-ia, então, de um apelo pessoal direto, isto é, positivo, quase explícito, sobre os outros. A direção de tal tendência é francamente num sentido antiestético, ou pelo menos, antiartístico ${ }^{11}$.

Os informalistas, em sua opinião, não conseguiriam distanciar o próprio ego da realidade e, por consequência, seus trabalhos somente seriam validados na significação particular que as formas apresentadas poderiam ter. Nesse sentido, um dos grandes méritos da abstração informal seria promover novamente, e de maneira intensa, o problema da significação e comunicação da arte abstrata ${ }^{12}$.

Mário Pedrosa e Ferreira Cullar compartilhavam a opinião de que a abstração geométrica deveria ser privilegiada na construção tanto de uma vanguarda brasileira quanto de uma história da arte moderna brasileira, além de acreditar que esse movimento ofereceria meios mais adequados para uma aplicabilidade efetiva da arte na sociedade. A arte concreta mostrava-se também como a manifestação artística mais adequada para um país como o Brasil que na década de 1950 atravessava um período de intenso crescimento econômico e florescimento industrial. Nesse sentido, o informalismo ofereceria riscos a essa empreitada. De acordo com Maria de Fátima Morethy Couto, a retrospectiva de Jackson Pollock no Museu de Arte Moderna de Nova York em 1957 e a Bienal de Veneza do ano seguinte, anunciada por Antonio Bento como o triunfo da abstração informal, marcaram a popularização do informalismo e a reorientação da abstração no Brasil, centrada no seu viés racionalista ${ }^{13}$.

O esforço de estabelecer o concretismo como a abstração brasileira está atrelado à ambição de construir uma vanguarda moderna nacional, o que permitiria aos artistas e críticos conquistar

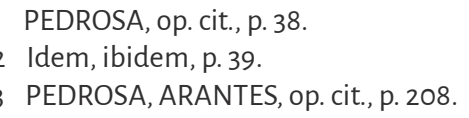


mais espaços culturais. Lygia Pape, ao comentar a ruptura entre os artistas abstratos da década de 1950 e os modernistas como Di Cavalcanti, Anita Malfatti e Tarsila do Amaral, afirmou: “(...) Portinari, por exemplo, era um artista oficial. Quer dizer, ele era chamado para tudo e mantinha uma produção praticamente oficializada"14. Pedrosa, por sua vez, ao comemorar a vitória de artistas concretistas na Bienal de São Paulo, comentou: "Os velhos maestros consagrados resmungam (sobretudo Segall), mas não são ouvidos"15.

Ao retomar a crítica de Mário Pedrosa a exposição "A arte internacional de uma nova era Informal e Gutai" é possível perceber as intenções ocultas ao reduzir os artistas japoneses a imitadores de Pollock e ao enfatizar que, embora Gutai possa ser traduzido como "concreto", eles não se relacionam com o concretismo brasileiro.

Ao comentar a obra de Jackson Pollock, Pedrosa afirma existir no seu trabalho um depósito de suas ânsias expressivas, de suas ejaculações projetivas ${ }^{16}$. E ainda aponta que o artista americano "(...) emaranha-se sem saída no próprio gesto (...)"17. Pedrosa defende também que movimentar-se durante o ato de pintar é um mecanismo banal promovido pelo informalismo para alcançar um dinamismo em suas pinturas ${ }^{18}$. No entanto, ao tratar da arte da caligrafia sino-japonesa, o crítico passa a considerar positiva a ênfase no gesto individual dos artistas, a movimentação ao redor do papel ao pintar, o imediatismo na criação das formas.

De acordo com Doryun Chong, o cenário artístico japonês durante os anos do pós-guerra foi caracterizado pela necessidade de elaborar novas teorias estéticas que buscassem unir arte e sociedade de maneira mais significativa. Marcadas pela perda da guerra, as preocupações sociais estabeleceram uma relação complexa com a produção de imagens, transformando a figura humana em formas bizarras, fantásticas e até abstratas ${ }^{19}$. Nesse sentido, movidos pela compreensão de que a ênfase na materialidade indicaria diferentes relações com o mundo material, os artistas veriam a geometria como um conjunto de leis que apenas postularia relações entre si e promoveria um afastamento dos objetos concretos. "A abstração geométrica era irremediavelmente vista como irrelevante por causa do distanciamento das questões sociais"20.

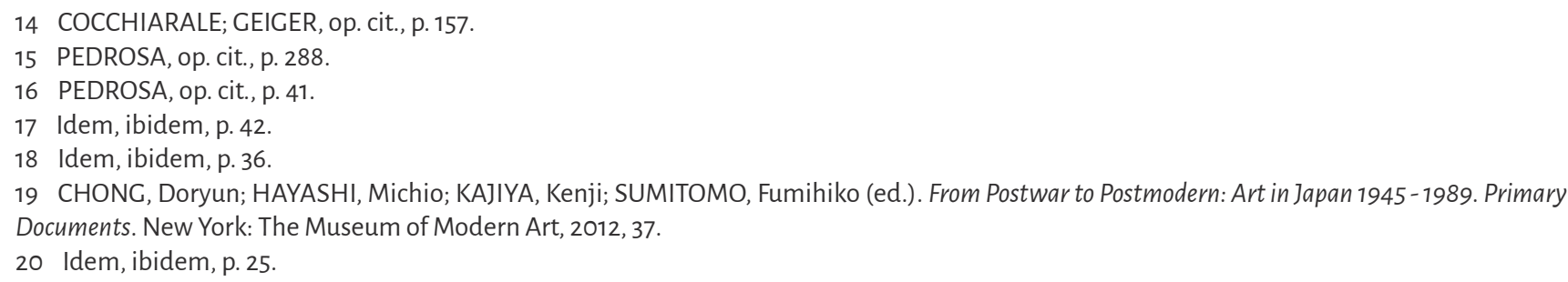


O crítico de arte Ichiro Haryu chamou de "tufão informal"21 a entrada do informalismo no Japão, marcada pela exposição “Art of Today's World”, curada por Taro Okamoto em 1956. No ensaio "Material and Humans" (1957), escrito e publicado durante a exposição citada, Haryu aponta que o informalismo foi um movimento que procurou recuperar a espontaneidade e a vibração do espírito do artista e se concentrou em transformar o espaço e os materiais em elementos operativos nos seus trabalhos ${ }^{22}$. O informalismo teria oferecido uma oposição ao "academicismo" da arte abstrata que se centrava em promover análises formais. Sua potência expressiva estaria primordialmente na materialidade da pintura, enquanto as formas e as cores seriam dados secundários. Podemos inferir que a ênfase na materialidade e sua capacidade de transformar as sensibilidades humanas em relação ao mundo concreto estavam na origem da compreensão de Haryu sobre o informalismo.

Hirai Shoichi aponta que o manifesto do grupo Gutai foi uma resposta ao debate sobre materialidade na arte após a introdução do informalismo no Japão ${ }^{23}$. Yoshihara afirmou no manifesto do grupo sentir simpatia pelas proposições informalistas ao promover uma arte livre de convenções formais, embora ele acredite que o Gutai possua maneiras diferentes de se expressar ${ }^{24}$. Outro fator importante para a boa recepção da abstração informal no Japão foi o contexto político em que este movimento se inseriu na França, associado ao desejo por liberdade após a desocupação nazista; os japoneses se viram em situação similar com a saída das forças militares americanas do seu país.

De acordo com Haryu, "Aquilo que é conhecido no período do pós-guerra como expressionismo abstrato destrói a relação entre forma e espaço existentes e incorpora a força da pincelada, sua tatilidade, e material na busca de uma expressão mais complexa de tempo, psicologia e ação"25. Atsushi Miyakawa, por sua vez, afirma que a matéria, embora seja apreendida por sua superfície, não comunica apenas uma exterioridade, comunica o potencial expressivo que guarda em si. E completa: "Se a consciência contemporânea da matéria corresponde à negação do sistema da forma, é precisamente porque a existência da matéria não ocorre na sua superfície, mas na sua interioridade e profundidade escondidas por trás da sua sombra (...)"26.

Shuzo Takiguchi defende que desde os tempos antigos a arte da caligrafia permeou profundamente a sensibilidade japonesa, por esse motivo os artistas nipônicos encontraram, em um

\footnotetext{
21 ERBER, Pedro. Políticas da abstração: pintura e crítica no Brasil e Japão, anos 1950. Poiésis. Publicação do Programa de Pós-Graduação em Estudos Contemporâneos das Artes da Universidade Federal Fluminense - n.14 (2009). - Niterói: PPGCA, 2009, p. 51.

22 CHONG; HAYASHI; KAJIYA; SUMITOMO, op. cit., p. 103.

23 ERBER, op. cit., p. 84.

24 MUNROE, Alexandra; TIAMPO, Ming. Gutai, Splendid Playground. New York: The Solomon Guggenheim Museum, 2013, p. 18.

25 CHONG; HAYASHI; KAJIYA; SUMITOMO, op. cit., p. 104.

26 Idem, ibidem, p. 109.
} 
primeiro momento, dificuldade em relacionar esta arte com a pintura moderna europeia ${ }^{27}$. No entanto, o informalismo, ao superar o debate entre figuração e não-figuração e enfatizar a superfície da tela no seu desenvolvimento expressivo, se aproximaria do território da caligrafia. Para Michio Hayashi, o informalismo funcionaria como um "filtro conceitual" para que os artistas realizassem uma aproximação entre a pintura e o shodô, a arte da caligrafia ${ }^{28}$. Podemos inferir que a ênfase na materialidade, no gesto criador do artista e na elaboração de diferentes procedimentos para a pintura caracterizaria o projeto de renovação das artes tradicionais japonesas promovidos pelo grupo Gutai, em particular a arte da caligrafia.

De acordo com Reiko Tomii, Jiro Yoshihara, ao comentar em um artigo de jornal sobre uma exposição de pintores norte-americanos, deu os primeiros passos em direção a discussão sobre "contemporaneidade internacional", um conceito histórico caracterizado como uma percepção compartilhada entre um dado local e o resto do mundo. "Olhando para esses trabalhos que mostram uma nova tendência, encontrei algo comum entre eles e nós. Isso compreende um compartilhamento de um 'sentimento da época', e me sinto muito mais perto desses artistas americanos do que dos artistas japoneses que trabalham com estilos ultrapassados"29.

Foi o crítico Ichiro Haryu, no entanto, quem articulou o conceito de "contemporaneidade internacional" no final da década 1960 ao apontar que os artistas japoneses não estariam imitando a abstração expressiva de Jackson Pollock, por exemplo, existiria uma experiência compartilhada entre os artistas de Nova York, Paris e Tóquio, ainda que os discursos da arte nipônica fossem percebidos por sua posição periférica em relação à modernidade ${ }^{30}$. Ou seja, o conceito de "contemporaneidade internacional" estabelece uma relação que não se configura como imitação entre as artes japonesas e as artes da América e da Europa. "No que diz respeito ao Japão, agora nós ultrapassamos o dualismo entre Oriente x Ocidente, a escolha entre Modernismo emprestado x Tradicionalismo japonês. Nós finalmente alcançamos a consciência da 'contemporaneidade' no sentido de uma 'contemporaneidade internacional'"31. No entendimento de Haryu, superar a dualidade Oriente $\mathrm{x}$ Ocidente trouxe uma dimensão internacional à arte japonesa contemporânea. Nesse sentido, o crítico defende uma história da arte mundial como uma rede de histórias locais conectadas por meio

\footnotetext{
27 Idem, ibidem, p. 74.

28 CHONG, Doryun (ed.). Tokyo 1955-1970: a new avant-garde. New York: The Museum of Modern Art, 2013, p. 115.

29 YOSHIHARA apud. TOMII, Reiko. "International Contemporaneity" in the 1960s: Discoursing on Art in Japan and Beyond. In: Japan Review. New York: vol. 21, 2009, p. 126.

30 Idem.

31 Idem, ibidem, p. 126.
} 
de ressonâncias, que ora são explícitas ora são implícitas.

Podemos inferir que tanto no Brasil quanto no Japão a crítica de arte durante as décadas de 1950 e 1960 teria privilegiado a arte abstrata como campo para disputas ideológicas; no Brasil, a abstração geométrica ofereceria meios para transformar as sensibilidades humanas, enquanto no Japão, a abstração informal seria um meio para atualizar as artes tradicionais e ampliar o debate artístico para dimensões internacionais. A crítica de ambos os países estaria preocupada em desenvolver junto aos artistas uma compreensão de uma arte que atuasse de maneira eficiente nas diversas camadas sociais e explorasse as relações que mantinham com as artes da América do Norte e da Europa, que entendesse o seu papel na construção de uma História da Arte mundial. 


\section{Referências Bibliográficas}

BOIS, Yve-Alain; BUCHLOH, Benjamin; FOSTER, Hal; KRAUSS, Rosalind. Art Since 1900: Modernism, Antimodernism, Postmodernism. New York: Thames and Hudson, 2004.

CHONG, Doryun (ed.). Tokyo 1955-1970: a new avant-garde. New York: The Museum of Modern Art, 2013.

; HAYASHI, Michio; KAJIYA, Kenji; SUMITOMO, Fumihiko (ed.). From Postwar to Postmodern: Art in Japan 1945 -1989. Primary Documents. New York: The Museum of Modern Art, 2012.

COCHIARALE, Fernando; CEICER, Anna Bella (org.). Abstracionismo geométrico e informal: a vanguarda brasileira nos anos cinquenta. Rio de Janeiro: FUNARTE, Instituto Nacional de Artes Plásticas, 1987.

COUTO, Maria de Fátima Morethy. Mário Pedrosa, Ferreira Gullar e a abstração informal no Brasil. In: Novos Estudos. São Paulo: Cebrap, 2000.

Por uma vanguarda nacional: a crítica brasileira em busca de uma identidade artística (1940-1960). Campinas, SP: Ed Unicamp, 2004.

ERBER, Pedro. After The Politics of Abstraction: Avant-Garde Art and Criticism in Japan. Tese (doutorado em Literatura Japonesa). Cornell University, CORNELL, Estados Unidos, 2009.

Políticas da abstração: pintura e crítica no Brasil e Japão, anos 1950. Poiésis. Publicação do Programa de Pós-Graduação em Estudos Contemporâneos das Artes da Universidade Federal Fluminense - n.14 (2009). - Niterói: PPCCA, 2009.

KEE, Joan. Situating a singular kind of 'action': early Gutai painting, 1954-1957. In: Oxford Art Journal, vol. 26. Oxford: Oxford University Press, 2003.

KUNIMOTO, Namiko. Shiraga Kazuo: the hero and concrete violence. In: Art History, vol, 36. Londer: Association of Art Historians, 2012.

MUNROE, Alexandra; TIAMPO, Ming. Gutai, Splendid Playground. New York: The Solomon Guggenheim Museum, 2013. PEDROSA, Mário; ARANTES, Otília (org). Modernidade cá e lá: Textos escolhidos IV. São Paulo, Editora da Universidade de São Paulo, 2000.

Política das artes. São Paulo, Editora da Universidade de São Paulo, 1995.

Mundo, homem, arte em crise. São Paulo: Editora Perspectiva, 2007.

SHOICHI, Hirai. The Action Painting of Kazuo Shiraga. In: Kazuo Shiraga: Painting Born out of Fighting. Azumino: Azumino Municipal Museum of Modern Art, 2009.

TIAMPO, Ming. Create what has never been done before! In: Third Text, vol. 21. 2007.

TOMII, Reiko. "International Contemporaneity" in the 1960s: Discoursing on Art in Japan and Beyond. In: Japan Review. New York: vol. 21, 2009. 